\title{
An Evaluation View of an Ensemble Artefact for Decision Support using Action Design Research
}

\author{
Dale MacKrell \\ University of Canberra \\ dale.mackrell@canberra.edu.au
}

Craig McDonald

University of Canberra

\begin{abstract}
This paper investigates the integration of content, context and process (CCP) into the Action Design Research (ADR) framework to account for the interplay of organisational issues in artefact design and development. The investigation is conducted through a case study in which successive ICT student teams incrementally build, over several semesters, a tailored, low cost business intelligence (BI) system as an ensemble artefact for an organisation in the not-forprofit (NFP) sector. During project development, CCP's human-centred approach to evaluation complements ADR's more prescribed technology-driven software testing. The integration of $\mathrm{CCP}$ into $\mathrm{ADR}$ as an evaluation view offers an holistic approach to assessing an ensemble artefact. The resultant conceptual framework is presented as a model with an explication of unexpected design and research outcomes.
\end{abstract}

Keywords: action design research; action research; design science; evaluation; qualitative; not-for-profit

\section{Introduction}

Scholarly articles of design science research in decision support systems (DSS) development have highlighted unresolved key issues that need attention: relevance, evaluation, theorising, and strategic focus, to name a few (Arnott \&Pervan 2012; Miah \&Gammack 2014). Arnott and Pervan, in 2005 and 2008, identified that the relevance and quality of DSS research would improve by increasing the number of case studies, especially interpretive field studies. More currently, Arnott and Pervan (2012) call for stronger theoretical contributions to design foundations and methodologies in DSS design science research while lamenting the dearth of articles in the contemporary and related field of business intelligence (BI) which has raised the expectations of managers for strategic-focussed enterprise-wide computer-based decision support ${ }^{1}$. Arnott and Pervan (2012) claim evaluation to be an endemic weakness in DSS design science research and recommend that multi-method evaluation including field-based review and action research be encouraged.

A contemporary approach that draws on action research and design science is action design research (ADR) which values both organisational relevance and technological rigour with the intention of extending design knowledge (Sein, Henfridsson, Purao, Rossi \& Lindgren 2011). ADR aims at building innovative IT artefacts interactively in an organisational setting. This socio-technical approach takes place through a predefined reflexive process to address a problem-solving situation while stakeholders learn from the intervention. Underlying ADR is a strong reliance on review through a cycle of building, intervention and evaluation (BIE) (Sein et al. 2011).

The notion of 'ensemble artefact' is proposed by Sein et al (2011, p.38) to reflect the view that organisational structures are embedded into the artefact during its development and use. The concept originates as an 'ensemble view' in the influential paper by Orlikowski and Iacona (2001, p.126) which restores a focus to the IT artefact in information systems (IS) research

${ }^{1}$ Sharda, Delen and Turban (2014) claim that DSS of the 1970s evolved into BI systems in the mid-1990s, with both DSS and BI systems having a focus on supporting decision makers. 
while recognising "the dynamic interactions between people and technology". Goldkuhl ${ }^{2}$ (2012; 2013) contests the transformation from 'ensemble view' to 'ensemble artefact'. In their rejoinder to Goldkuhl's critique, Purao, Henfridsson, Rossi and Sein (2013, p.76) retort that the term, 'ensemble artefact', is 'succinct shorthand' for a more holistic view of the organisational and social context of an IT artefact rather than merely as a software-hardware tool as emphasised in traditional design science. Debate with respect to the troubled conceptual shift in nomenclature is not to the forefront of this paper. In a similar vein, this paper does not dwell on the distinction in terms, design science, design research and design science research, leaving this to other authors (Winter 2008, Baskerville 2008). In the main, this paper refers to design science research using the acronym DSR for simplicity.

Purao et al. (2013, p.79) stress that ADR is still an 'open endeavour'. The emphasis of this paper is on evaluation, thus heeding concerns regarding 'user-centredness' as a significant but neglected aspect of DSS design (Miah \& Gammack 2014) as well as issues of relevance, theorising, and strategic focus (Arnott \& Pervan 2012). From a growing body of evaluation literature, Stockdale and Standing (2006) recognise the absence of an evaluation framework to reflect social, political and cultural factors that influence project development. They argue that many IS evaluations overlook the social context in organisations by focussing on the IT artefact. They propose an interpretive evaluation framework by adapting the content, context and process (CCP) model from Symons (1991). CCP, combined with technical testing, offers a comprehensive and more holistic appraisal of IS projects. The value of holistic evaluations in $\mathrm{ADR}$ is illustrated in this paper in an ongoing research project in the not-for-profit sector.

This paper has significance from three main perspectives: practical, theoretical and methodological. The practical contribution of the project is to design a data mart and reporting tools in the cloud to capture, store and retrieve quality integrated data as first steps to a BI solution. The construction of operational IT artefacts takes place progressively in Connections ACT, a local Canberra not-for-profit organisation (NFP). The aim is to keep costs low and to utilise available resources - student teams, funding from grants, university technical expertise, community support, and open source software options. This project is ongoing and empirical, with two to four student teams each semester allocated to the project until the planned implementation in late 2016. The study has interventionist goals and serves as a means of deriving a design guide useful to other NFPs wishing to implement BI using ADR. This is the methodological contribution of the study.

This paper continues with a discussion of ADR positioning the paper within existing research and follows with an illustration of evaluation in the Connections ACT setting. From this project, a CCP evaluation model, integrated with $\mathrm{ADR}$ as an evaluation view, extends the conceptual work of Sein et al. (2011). This could be described as 'partial theory' according to the classification by Gregor, Imran and Turner (2010) with attention on the socio-technical artefact in its setting, design principles of form and function, and associated theories. The integrated and extended framework is modelled and explained in the discussion section while future research is proposed in the concluding section.

\section{Explaining Action Design Research}

Action design research (ADR) is a research approach advanced by Sein et al. (2011) to address a problem-based situation by building innovative technical artefacts in an organisational setting using a structured and predefined process and to learn from the activity. ADR is a methodological solution which combines both canonical action research (AR) with its enduring research tradition (Davison \& Martinsons 2004) and design science research (DSR) being an established research approach in the IS discipline (Hevner, March, Park \& Ram 2004). AR, in an iterative process, investigates a contextual phenomenon through researcher intervention and generates theory through change, learning and reflection with scant regard for the IT

${ }^{2}$ Goldkuhl (1981, cited in Goldkuhl 2013) formulated the slogan of information systems as social systems only technically implemented. 
artefact. On the other hand, DSR positions IT artefacts at the core of the IS discipline yet may fail to adequately recognise the role of the organisational and social context shaping both the design and the deployed artefact (Sein et al. 2011).

The ADR approach proposed by Sein et al. (2011) builds on Cole, Purao, Rossi and Sein (2005) to prescribe four stages within which are seven principles, set out in Table 1. This paper concentrates on Stage 2 in Table 1: Building, Intervention and Evaluation (BIE). Sein et al (2011, p.40) contend that ADR is an innovative research method which recognises that the artefact, framed by March and Smith (1995, p. 256) as 'constructs, models, methods, and instantiations', emerges from interaction with the organisational context. Figure 1 shows a typical BIE which suits ADR efforts that emphasise creating an innovative technological design at the outset, termed the IT-dominant BIE (Sein et al. 2011).

\begin{tabular}{|l} 
Stage 1: Problem Formulation \\
Principle 1: Practice-Inspired Research \\
Principle 2: Theory-Ingrained Artefact \\
Stage 2: $\quad$ Building, Intervention and Evaluation \\
Principle 3: Reciprocal Shaping \\
Principle 4: Mutually Influential Roles \\
Principle 5: Authentic and Concurrent Evaluation \\
Stage 3: $\quad$ Reflection and Learning \\
Principle 6: Guided Emergence \\
Stage 4: $\quad$ Formalisation of learning \\
Principle 7: Generalised Outcomes
\end{tabular}

Table 1. Action Design Research Stages and Principles (Sein et al. 2011)

Sein et al. (2011) use an alternative, slightly modified diagram with deeper end-user participation to describe ADR efforts to generate design knowledge when the primary source of innovation is organisational intervention, that is, organisation-dominant BIE rather than IT-dominant BIE. BIE of the ADR approach draws on three principles: reciprocal shaping, mutually influential roles, and authentic and concurrent evaluation. Together, these principles emphasise the inseparability of the domains, the IT artefact and the organisational context, that influence the ADR project (Sein et al. 2011, p.43).

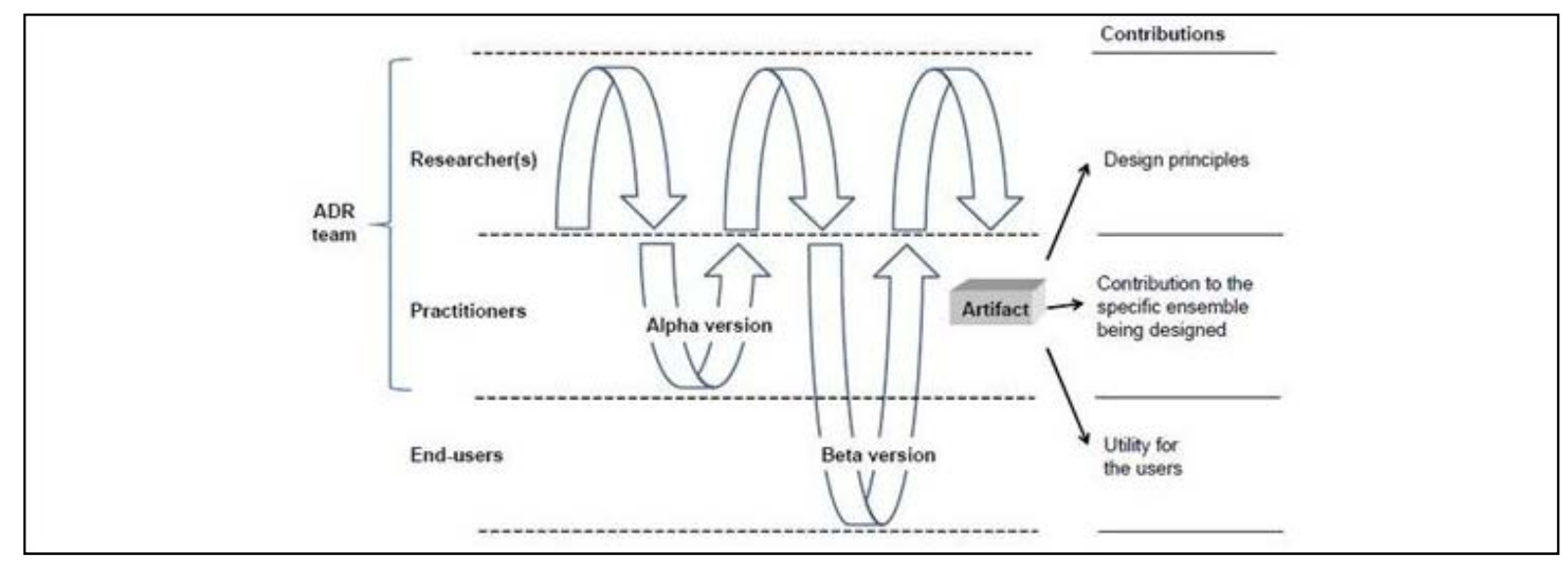

Figure 1: The ADR Generic Schema for Building, Intervention and Evaluation BIE (Sein et al. 2011) 
The relationship between AR and DSR has been widely analysed for some time (Iivari \& Venable, 2009; Järvinen 2007; Maccani, Donnellan, \& Helfert 2015; Papas, O’Keefe \& Seltsikas 2012). Iivari and Venable (2009) critique the paradigmatic assumptions of AR and DSR by examining the ontology, epistemology, and methodology of each to conclude that ADR can reconcile divergent view but care needs to be taken due to fundamental philosophical differences. Papas et al. (2012) express less enthusiasm for ADR, suggesting that canonical AR may suffice assuming the criteria of interventionist research are satisfied, noting that the IT artefact is normally a by-product of AR not the goal, while J ärvinen (2007) claims AR and DSR may be used together in a study with relative ease.

The philosophical foundations of AR and DSR have been studied by Maccani et al. (2015, p.7), drawing on Iivari and Venable (2009). From the preliminary findings of their research-inprogress, Maccani et al (2015) determine that DSR assumes a positivist epistemology (especially in the engineering field) and is more likely to be design-derived, implying a technical approach to evaluation of the IT artefact with software testing expected to be performed. ADR, on the other hand, because of its participative nature, is more likely to have an anti-positivist or interpretivist position as an underlying assumption with the artefact being shaped by the characteristics of the evaluating individual such as the user.

\subsection{Views on Evaluation}

Evaluation has long been a topic of discussion in the AR and DSR literature with Winter (2008) and Goldkuhl and Sjöströmb (2015) pointing out the lack of evaluative guidelines. It is noted by Sein et al. (2011, p.39) that in most DSR efforts, "awareness of the problem precedes the development of the artefact", which is then followed by evaluation. This is essentially the build and then evaluate' cycle (Hevner et al. 2004; March \& Smith 1995) where evaluation is recognised as a separate and distinct activity. Goldkuhl and Sjöströmb (2015) insist that evaluation should occur at all stages of the enquiry process, citing ADR as an approach which integrates evaluation into building and intervention activities.

There is a strong motivation in ADR to capture organisational aspects of the intervention in a 'meta-approach' to evaluation combining elements of both AR and DSR. Both BIE schemas by Sein et al. (2011), namely IT-dominant BIE and organisation-dominant BIE, demonstrate an evaluation cycle for the alpha version of the artefact which is formative and another for the beta version which is summative. Sein et al. (2011) claim that controlled evaluations may be difficult to achieve in an $\mathrm{ADR}$ project due to the emergent nature of the artefact. In prescribing alpha and beta evaluations, Sein et al. (2011) specify evaluation timings but give a lower profile to the details of what, why, who and how of ADR evaluation. In prototyping situations or when project goals are indistinct, it is possible that more iterations are required, in which case, evaluation cycles are dependent on the version of the artefact. In the section following, we examine the content, context and process (CCP) evaluation framework from Stockdale and Standing (2006) to assess its suitability as an interpretive methodology to supplement positivist technical assessments.

\subsection{Where does the CCP Model of Evaluation fit?}

Stockdale and Standing (2006) note the preponderance of technical assessments in IS evaluations. They propose an interpretive approach for evaluating the complex interplay of organisational issues to complement software testing. Stockdale and Standing (2006) refer to the what, why, who, when and how of IS evaluation in their paper extending Symon's (1991) content, context and process (CCP) framework. The 'what' is represented by the content construct to discern which measures and metrics comprise the evaluation, confounded in IS with fewer measurable societal and organisational impacts. The context concept requires the 'why' and 'who' to be considered, this being internal and external organisational influences and various stakeholders. The process concept takes into account the 'when' and 'how'. Importantly, Symons (1991, p. 211) argues for evaluation to continue throughout the project lifecycle, thus reducing the risk of failure. 
Likewise, Pries-Heje, Baskerville and Venable (2008) propose a strategic framework for DSR evaluation. They refer to the what, when and how of DSR evaluation, namely, product and process, ex ante and ex post, and artificial or naturalist settings, with lesser focus on the why and who. In the ex ante perspective, a technology artefact is evaluated before selection while in the ex post perspective, it is evaluated after appropriation. Pries-Heje et al. (2008) explain that DSR evaluation is often oriented towards ex post timings even though economic costs are paramount in ex ante analysis. This is certainly true for the private sector. In both public and not-for-profit sectors, the profit motive is less, with the recognition that other factors are at play such as concern for social well-being.

As a socio-technical methodology, it would be expected that ADR evaluation covers both ex ante and post ante perspectives. MacKrell and McDonald (2014) contend that human- and technology-centred evaluations together produce more complete knowledge than evaluations which focus separately on either social or technical dimensions. This paper takes another look at $\mathrm{ADR}$ evaluation, to bring together the CCP framework and relevant concepts from existing DSR evaluation to propose an ADR evaluation view.

Cleven, Gubler and Hüner (2009) claim that evaluation should not be an isolated activity. In their study, they surveyed existing methods of evaluating DSR artefacts, identified characteristics then drew up an evaluation framework. Despite their comprehensive efforts, there is little emphasis on the organisational setting. For the purposes of this paper, we will initially adopt the definition of evaluation offered by Scriven (1998, p.85) and cited in Cleven et al. (2009):

Evaluation is the process of determining the worth, merit, or significance of entities; and evaluations are the outcome of that process. Evaluation may be external or internal, or a mix of these; and it may be quantitative or qualitative, or a mix of these. It is strongly although not always sharply distinct from explanation.

This evaluation definition is re-assessed at the conclusion of this paper in light of our findings.

\section{Illustrating ADR with a Case Study}

A research approach for the study was sought which was prescriptive in the IT artefact development lifecycle (IT-dominant BIE) necessitating technology-driven testing. The research approach also needed to be socially participative, reflective and reflexive (organisation-dominant BIE), requiring a qualitative evaluative method, such as that offered by CCP. The features of ADR fulfilled these requirements and guided the project's development in a naturalistic organisational setting.

\subsection{Research Site}

The project is a case study with Connections ACT Incorporated, a local Canberra community organisation committed to helping disadvantaged communities and families who are homeless (or at risk of becoming homeless). Connections ACT consists of 18 paid staff who assist over 3,000 people in the ACT annually through two services: First Point, the central intake service for the homeless, and CanFaCS, a service for homeless fathers and their children.

Information systems in Connections ACT consist of:

- $\quad$ Excel spreadsheets for managing the occupancy and maintenance of properties for CanFaCS. Data related to nine properties and rental bookings are located in various non-structured repositories such as spreadsheets and whiteboards matrices.

- $\quad$ SQL database called SHIP (Specialist Homelessness Information Platform) with a Web-based interface built by a Melbourne-based external consultant for the collection of demographic homeless client data for First Point. The system has limited standard and customised reporting features.

- $\quad$ SQL database called Daily Capacity Report (DCR) developed with Alpha 5 technology built for First Point by a Melbourne-based external consultant for 
tracking accommodation and outreach availability. The system has limited reporting features.

- $\quad$ BitCloud is a commercial enterprise for hosting applications in the cloud at a commercial financial cost to Connections ACT.

The managers at Connections ACT struggle with onerous compliance and ad hoc reporting since often client data capture is cumbersome, data quality is poor, information retrieval is haphazard, and software is inadequate. NFPs such as Connections ACT are increasingly reliant on accurate and quickly-retrievable organisational data for regulatory reporting and on-going funding. This is difficult to realise for most NFPs since the software available is predominantly suited to organisations in the for-profit sector which have different needs and resource-bases, and are not liable to compliance reporting as are NFPs (MacKrell 2012). By addressing Connections ACT's data and software challenges, this project will enable the organisation to concentrate its limited resources on core business (helping the homeless).

\subsubsection{Research Approach}

A pragmatic approach to the project was adopted. This is described below within the four stages and seven principles of ADR proposed by Sein et al. (2011) and set out in Table 1. While the stages of ADR are portrayed neatly in sequence, in reality, with reliance on evaluation, reflexivity and intervention, the stages overlap and parallel during iterations.

Stage 1: Problem Formulation

In early 2012, the Executive Officer (EO) of Connections ACT contacted the lead researcher for assistance with their deteriorating DCR database. The initial fact-finding stage of the project took place in late 2012, utilising a human-centred 'sense-making' approach to identify the technical, organisational, informational and decisional needs of Connections ACT. The lead researcher conducted nine single face-to-face, in-depth interviews with senior Connections ACT managers and one board member, and three group meetings with University of Canberra BI and data warehouse experts. This provided background to the problem enabling basic requirements elicitation. Analysis of interview transcripts and organisational documents suggested that silos of data existed in the organisation due to non-linking databases and spreadsheets, in turn thwarting the extraction and use of the valuable information they contained. As an upshot of this phase, it was decided that a practical outcome of the project would be the design, development and deployment of stable and reliable data repositories and IS management systems as BI artefacts for both First Point and CanFaCS as the preliminary stage to BI.

As stated earlier and presented in Table 1, Sein et al. (2012) propose seven principles within the four stages. The two principles which apply in the Problem Formulation stage are Principle 1: Practice-Inspired Research and Principle 2: Theory-Ingrained Artefact. The research activity is problem-inspired since the trigger for the project was a phone call from the Connections ACT EO who was receptive to practice-inspired research and welcomed a joint venture with the University of Canberra. The projected artefact is theory-embedded, informed in the initial stages through sense-making, and structured via tailored industry frames of reference including business process models and mapping.

\section{Stage 2: Building Intervention and Evaluation (BIE)}

Gregor and Hevner (2013, p.339), in their recent paper, use the term 'program' to define a significant research program which "typically encompasses many researchers over several years", while a 'project' refers to a "portion of a larger program" which may be interim attempts at theorising. The researchers, in this paper, remain reticent about terminology but stay with the terms 'project' and 'mini-project' because of the initiative's strong practical purpose in a single organisation.

The entire project is a complex long-term undertaking, broken into mini-projects, to build a BI solution for a NFP, Connections ACT. The BI deliverables consist of numerous data, software and process artefacts, which will be described in detail in a future paper. The project is part of 
a work-integrated learning (WIL) subject offered as a capstone to students in their final semester of studies. Each student team is provided with a proposal of essential and desirable deliverables as a distinct mini-project expected by the end of semester. Student teams, usually comprising a project leader, analyst, developer and tester, build the artefacts. The teams are well supported with scaffolding and mentoring each semester by the subject convenor, tutor, project coordinator, university and community technical experts, and importantly, the client. Teams are expected to fulfil documentation requirements, complete a comprehensive testing schedule, and deliver to the client a functioning artefact, all of which is assessed and graded. These assessments are formal, with a concentration on technical and tangible aspects of system design and development.

The social dimension is called into play through less formal qualitative evaluations of student teams, client users and managers. These interviews/meetings are face-to-face, semistructured, single or team conducted at several points in the semester: at the start and end of each semester, and mid-semester and/ or any crises point. While these interviews/meetings are comparatively informal, they are guided by a prepared interview script or meeting agenda.

The principles of Sein et al. (2011) which apply at the Building, Intervention and Evaluation stageare Principle 3: Reciprocal Shaping, Principle 4: Mutually Influential Roles, and Principle 5: Authentic and Concurrent Evaluation. Reciprocal shaping is described as the iterative process to construct and reconstruct both the IT artefact and organisational context when solving 'wicked problems'. One of the so-called 'wicked problems' is Excel spreadsheets, created by the client as a stop-gap measure in lieu of a structured data repository (Houghton \& MacKrell 2014). This exemplifies mutually influential roles which transpire when project participants learn from each other. As student teams progressively develop a database to replace Excel spreadsheets, the client managers steadily become aware of technical and business potentials from storage, analysis and retrieval of data. This realisation leads to greater commitment to the project by the clients and the prospect of solution intervention by the researchers. A senior manager stated in an interview, "Yeah. Look, I suppose the key takeaway for you today is that certainly I'm still quite strongly committed to this project. We've both invested an awful lot in it, as have the students, and we're quite conscious of the need to adapt and be creative and look for better, more productive ways of doing things".

Regarding authentic and concurrent evaluation, it has already been identified that evaluation is a key characteristic of this project with evaluation cycles dependent on more than routine ex ante and ex post alpha and beta versions, with artefact development complicated by discrete building phases associated with varying teams.

\section{Stage 3: Reflection and Learning}

The principle which applies at the Reflection and Learning stage is Principle 6: Guided Emergence, referring to the interplay between guidance through design, and emergence through evaluation. The learning stage relies on evaluation, both human- and technologycentred to encourage reflection and ensure more useful project outcomes.

McKay, Marshall and Heath (2010) argue that technology-centred concepts of DSR have been too limiting, and that human-centred design science should be built-in. The project involves many stakeholders: students, teaching staff, technical experts (university and community), clients, project coordinators, and researchers. All of the actors have a story to tell, not least of all the students as part of their capstone learning experience. Mutual learning takes place which is multi-faceted: being technical, social, organizational and educational.

While debate continues regarding the role of theory and theorising in DSR (Cole et al. 2005; Venable 2006), ADR affords the capacity to critically reflect on activities, then formulate and utilise theories to embody statements of knowledge for its creative practical activities. This argument is consistent with Gregor's theory for design and action which says "how to do something" giving prescriptions of "methods, techniques, principles of form and function" (Gregor 2006, p. 620). 
Gregor et al. (2010) note that DSR draws on theory we already know, otherwise known as kernel theory or justificatory theory. In this case, it is sense-making theory and 'small wins' theory. Weick (1984) in "Small Wins: Redefining the Scale of Social Problems", explains that small wins help to create an environment where change is not overwhelming and therefore more likely to happen. In order to solve massive social problems, Weick (1984, p.43) defines small wins as a "series of concrete, complete outcomes of moderate importance". The strategy of focusing on "a series of controllable opportunities of modest size that produce visible results", works directly on the construction of a problem and indirectly on its resolution. Once a small win has been accomplished, forces are set in motion favouring another small win.

There are important emergent theoretic topics such as user participation (Marcus \& Mao 2004) and IS design (Markus, Majchrzak \& Gasser 2002), still to be pursued. The study touches on technical design topics such as the open source software options to build IT artefacts allowing NFPs to enter theBI and data warehouse arena at reasonable cost, applicable to their needs (Klawans 2006).

\section{Stage 4: Formalisation of Learning}

The study is a combined venture of Connections ACT and the University of Canberra. The situated practice-based learning of both design principles and workplace change will be generalised as a conceptual framework extendable to the not-for-profit sector. The intent at this juncture is to disseminate new knowledge to share through publishing papers, conducting workshops, and instigating organisational change. This activity Formalisation of Learning complies with Principle 7: Generalised Outcomes, discussed further in the concluding section of this paper.

\section{Formulating a Socio-Technical Evaluation Framework for ADR}

In this section, both social appraisals as the CCP approach, and technical audits as traditional project milestones are discussed in terms of the project, especially in the BIE stage. Because of the nature of the project, the timing of evaluations is recurrent and iterative, not limited to ex ante and post ante for alpha and beta versions (Pries-Heje et al. 2008; Sein et al. 2011). PriesHeje et al. (2008) drawing on Venable (2006) refer to artificial and natural settings. This is a work-integrated learning (WIL) project: WIL being an umbrella term for learning activities such as activity-based learning, work-based learning and co-operative education, with attempts to link learning in academic and practice settings. WIL is not easily defined because it covers a diverse range of activities from internships and placements to real client projects and other practical, contextualised tasks (Fitch 2011). While much software testing takes place in an artificial setting, such as the university, the client is a real organisation which is a natural setting. As well, the opinions of stakeholders emerge as highly significant for shaping both product (BI artefact) and development processes, thus increasing the chances of project realisation. For this project, technical success was broadly defined in terms of releasing to the client functioning and useful software without too many disruptions. Social outcomes for the project were never clearly articulated but emerge as the study took form.

\subsection{Social Evaluations: CCP integrated into ADR}

In their paper, Stockdale and Standing (2006) draw on Symon's (1991) content, context and process (CCP) framework to propose an holistic approach to evaluation in information systems (IS). The organisational, political and cultural factors that influence artefact development incorporate the social aspects of appraisals. In other words, the what, why, who, when and how of IS evaluation. As explained by Stockdale and Standing (2006), the 'what' in the project lifecycle is represented by the content construct to know what is being measured and which metrics, if any, comprise the evaluation. The element of context requires the 'why' and 'who' to be considered, these being internal and external organisational influences and various stakeholders. The process construct takes into account the 'when' and 'how'. Importantly, Symons (1991, p. 211) argues for evaluation to continue throughout the project lifecycle, thus reducing the risk of failure. CCP applied to the case study is discussed below. Although CCP 
constructs are categorised separately, in reality they are intertwined and difficult to pull apart for analysis.

\subsubsection{Content (what is evaluated)}

The 'what' is both the BI artefact (technical details are explained briefly in the section below on Technical Testing in $\mathrm{ADR}$ ) and the processes employed to construct the artefact within the organisational settings of university and client, and the means by which assessments are performed. Measurements are not generally used for qualitative appraisals. Rather, assessments are in the form of interviews conducted by the researchers at regular intervals during the project lifecycle. These interviews are recorded, analysed and interpreted according to the researchers' frame of reference, and triangulated though student interviews and the reflective log written by the lead researcher.

Before the start of every semester, the researchers meet with the client, a meeting usually attended by four senior managers - one manager from First Point, one manager from CanFaCS, and both the Executive Officer and Business Manager from the parent organisation Connections ACT - to deliberate over the following:

- $\quad$ Status of the project: What progress was made over the last semester? What progress is expected over the coming semester?

- Team-level deliverables: Is the scope of the mini-project achievable for each team? Have the teams produced the deliverables?

Once the project had been ongoing for two semesters, the client managers gain confidence in their abilities to comment on the progress of the project. This was welcomed by the researchers. As the Business manager stated on behalf of the other managers:

Even if we don't quite achieve the big vision this semester, it's still a good step on the way I think. I guess there are a couple of things that I'm really looking for an outcome on. That is a better sense of coordination around what the teams are doing, and the second thing is around being clear about what they're actually working on and what they're capable of delivering by the end of this semester.

Regular meetings with the client are invaluable with decisions made in a participative manner, this being the modus operandi of many NFPs (MacKrell and Van Den Boogaard 2012). For example, consensus was reached amicably at the meeting held prior to the incoming semester, when the Business Manager confided:

Well, at the start of the meeting, I probably would have been hesitant to say yes we'll go with three [mini-projects] but the data warehousing one seems to - it will probably require minimal amount of input and engagement from us. So happy to see what the view of others [managers] is on that score. But it seems like it's viable to go with three [mini-projects].

The information gathered at these meetings is triangulated through consultations with student teams and the research log. Every semester, new student teams are set up by the subject convenor. The researchers have little control over the composition of the student teams, therefore, previous experience, knowledge and skills of team members are rarely known. Meetings with student teams take place a week or two after they are allocated to teams and are assigned their project with the prepared proposals. During the semester, the number of meetings with student teams is directly proportional to the amount of difficulty they are experiencing. That is, the more difficulty, the more meetings with both the researchers and the university technical experts who are mentoring the students. All teams are interviewed for a closure meeting after their final presentation and exam. With their final presentations and exams behind them, students tend to be more honest, contemplative and critical in their assessments. For instance, one student commented: "T think it was a good experience. Definitely in terms of stakeholder management and stuff like that. If it was smooth sailing, we probably wouldn't have learned anything ...". 
Another form of qualitative socially-derived evaluation is the research log documented regularly and reliably by the lead researcher. This log is invaluable for verifying names of stakeholders, dates of activities, decisions made at meetings, and so on. Together with academic assessments related to software and project progress, as discussed in the section on technical audits below, they form a holistic appraisal of project content.

\subsubsection{Context (who is evaluated, and why)}

Stockdale and Standing (2006) refer to internal and external influences on a project. Dealing first with internal influences of the project, the sway of stakeholders, as the 'who', was often compelling and conflicting. A dilemma for students was the prioritising of client and academic demands. Whom do the students please? One student agonised when waiting for the client to respond to a query expressed this, "so we have two sides to consider, client and university. If we wait for the client and try and reach a solution, we might fail university ... We are learning to use pressure to advantage". The situation emulates complex and competing workplace realities.

There is a tendency to forget that incoming teams are also stakeholders. Handing over to a new team is facilitated by comprehensive handover documentation and the latest source code from the previous team. Additionally, the EO of Connections ACT has recognised the hurdles of transferal and briefs the teams at an induction session early in the semester, soon after new teams have formed. This has proven to be very effective, especially in reducing lag time as new teams settle in and familiarise themselves with the organisation and the technical complexities such as BitCloud (Koparkar and MacKrell 2015).

Regarding external influences, an important stakeholder is the ACT Government. Strategic proposals by the directorate (ACT Government) to extend First Point central intake service for the homeless to other vulnerable citizens such as those with disabilities is 'in the pipeline', implying potential for growth. The Business Manager elucidated:

... we are still in a wait and see kind of environment for policy direction around housing and homelessness from the new government. But also because we're currently participating in an initiative by the ACT Government to look at building one human services gateway here in the ACT ...so we manage the system that - the central intake system for homelessness but there are also gateways for disabilities, for child youth and family support.

This was confirmed by the Executive Officer of Connections ACT, as such:

Okay. J ust in a nutshell my understanding is that the ACT Government is looking at better integrating services but looking at a central intake model for human services more broadly... the DCR is virtually the only successful [software] tool in town that gets notifications of vacancies and places people into them. We do that in homelessness but clearly that could be in ... other sorts of human service deliverables. So its applicability to the very core business of what human services is ...is becoming more and more valuable.

The context in which the project is being developed is the 'why' influence. The client is operating in a turbulent environment, dependent on funders for survival; hence, the reference to the DCR as a successful tool is pertinent as Connections ACT managers consider commercialisation of their software in a strategy towards social enterprise, an effort to decrease dependency on tenuous grant funding.

\subsubsection{Process (when and how evaluation occurs)}

Pries-Heje et al (2008) classify evaluation settings as either artificial or naturalistic. Artificial evaluations occur in a contrived, non-realistic manner, such as simulations and software testing. Natural evaluations explore performance to solve real problems in a real environment such as an organisation. The students tested their software artefacts in both settings, at the university and at the client's premises to demonstrate functionality and achieve client acceptance sign-off. 
During the lifetime of the project, there are as many iterations of development as there are semesters. The researchers determined it was essential to conduct evaluative interviews at important intervals. These evaluations are pre-semester and normative (ex ante), and post semester and summative (ex post). Processes to be adopted during the semester are discussed at the pre-semester meeting with the client managers. Further meetings with the client take place at the end of semester, and at any critical points during the semester. Occasionally, this has resulted in somevery frank discussions, as evident in the dialogue below, from the Business Manager.

That with the benefit of hindsight it was probably a bit too ambitious, that it probably could have done with a greater sense of coordination, certainly early in the semester. Probably the handover from the semester one student teams wasn't doneas effectively as it could have been done. There were some issues around the process and our availability and connections when the students needed to talk to us.

Process evaluations are fundamental for shaping the products and conduct of the project. It is inevitable that all stakeholders, researchers, developers and clients, err occasionally. Adjustments need to be made reflexively. This has the effect of building a more robust community of practice for the discussion of issues. The Business Manager, speaking on behalf of the other managers, said:

All of this work fits within the broader scheme of things for us. We need to adapt and change or there won't be a Connections ACT in the future. So you know all the work that we're doing, not just this piece of work, but other things that we're doing around social enterprise initiatives, common ground, are looking for other sources of more diversified funding.

The small wins approach was encouraged during the project to give the client confidence in the ability of teams to produce a working solution. As disclosed by a team project manager, "If we gave her [client manager] a database right at this time, she would have nothing that she could actually use. That's why I put in the reporting part ....". At the start of semester, each student team was provided with specifications articulating essential and desirable deliverables. Nevertheless, some leeway was encouraged so that each team could account for its strengths and weaknesses. The concept of small wins aligns well with ADR and its attention to evaluation and intervention, with the incremental building of IT artefacts through iterations (Weick 1984).

\subsection{Technical Testing in ADR}

Maccani et al. (2015, p.5) subscribe to both positivist and anti-positivist assumptions underpinning ADR philosophy. Design processes of BIE lean towards anti-positivism, being highly participatory and socially constructed. Methodologies for building and testing of the artefact are more prescriptive, although not discussed in any great depth in this paper. Software testing is standard for any project to demonstrate the worth of the artefact through pre-determined criteria such as utility, efficacy, validity and quality (Gregor and Hevner 2013). Evidence of software quality is contained in written specifications and documentation such as Project Charters, models of Entity-Relationship Diagrams (ERDs), Use Case Diagrams, testing schedules etc as well as in student team reports and presentations, as mandated by academic requirements. Much of this documentary evidence is built and evaluated in an artificial environment prior to client acceptance in a naturalistic organisational setting where every effort is made to involve the end-user client and researcher throughout the process.

\section{Discussion of Findings}

The ADR approach as presented in Table 1 was adopted for the project. ADR offers a means of bridging the conceptual gap between dichotomies of social versus technical, informal versus formal evaluations, and artificial and naturalistic, and thereby overcoming concerns regarding philosophical disparities (Iivari \& Venable 2007). CCP-driven evaluations have contributed to producing the holistic product-process insights of an ensemble artefact. By integrating CCP 
social evaluations and technical audits into the ADR approach, the BIE generic schema described by Sein et al. (2011) in Figure 1 is no longer representative of the project developed as a non-commercial undertaking for a NFP. An extended version of Sein's BIE generic schema in Figure 1 is modelled in Figure 2 with insights from our study. In the following text, the number in parenthesis followed by dot points loosely corresponds to annotations in Figure 2.

\section{(1) Context (why and who is evaluated)}

- $\quad$ Changing context influences the motivation of all stakeholders, for example, the client is keen to develop a social enterprise culture for the NFP

- $\quad$ ACT Government as a stakeholder sets regulatory pressures

- $\quad$ Executive officer is the project champion and vital to the project

- $\quad$ Client managers and users are influential stakeholders

- Incoming student WIL team is considered a stakeholder

- University and community mentors and experts are stakeholders

\section{(2) Content (what is evaluated)}

- $\quad$ Technical and social evaluations required to improve project's chances of success by shaping the project closer to the needs of stakeholders. Evaluations are instrumental to inform learning and knowledge through critical reflection.

- $\quad$ Strategic goal of project is clear however precise aims are not distinct sinceworking from an aspirational top-down rather than a grass roots bottom-up approach

- $\quad$ Progress of mini-projects towards project aims is incremental, dependent on many variables such as learning, skills and abilities of student teams, much of which is unknown before the start of each semester

\section{(3) Process (when and how does evaluation occur)}

- Iterative development periods for IT artefacts has discrete, short time periods of one semester

- $\quad$ Technical design, building and evaluation of IT artefacts is embedded into academic assessments

\section{(4) Research Outputs (research contributions, design principles, ensemble} artefact, interventions)

- $\quad$ Client takes a cautious approach, aware of student team limitations. Concept of 'small wins' by teams is important to build client confidence

- $\quad$ Procedures help to mitigate handover delays at start of each semester with documentation on status of project from previous student team and instructions on BitCloud access

- Induction session are arranged by client Executive Officer for each new team

- $\quad$ Regular and recurring contact with client by teams is planned

- Use of open-source software reduces costs

- Interventions occur in both educational and organisational practices

In summary, socio-technical evaluations conducted within the ADR framework have revealed unexpected themes, such as additional iterations, careful stakeholder management, and design initiatives to be included in a BIE generic schema as design guidelines for community projects. These have contributed to shaping the project to suit the needs of all stakeholders: the client Connections ACT, WIL students, and the researchers. The Executive Officer communicated his gratification with the words "... a shared commitment, you're sticking with us, we're sticking with you. We're learning as we're going along." 


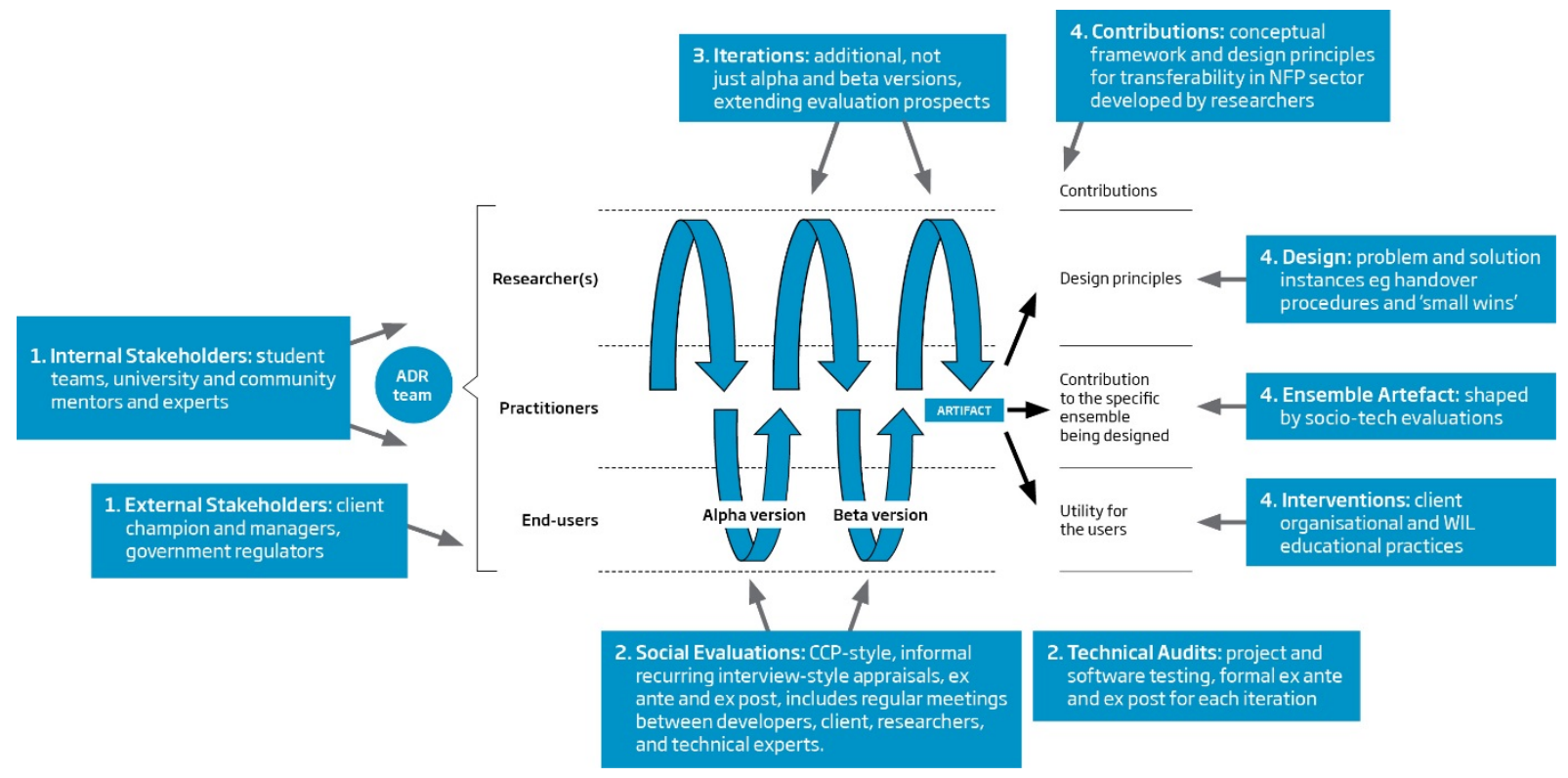

Figure 2: The ADR Generic Schema for Socio-Technical BIE (adapted from Sein et al. 2011) incorporating CCP as it applies to the case study in the areas of

1. Context eg stakeholder evaluations

2. Content eg socio-technical evaluations

3. Process eg supplementary iterations

4. Research outputs eg research contributions, product-process design insights

As indicated at the start of this paper, key issues of relevance, evaluation, theorising, and strategic focus have been identified as neglected and unresolved in DSS research (Arnott \& Pervan 2012; Miah \& Gammack 2014). Human activity is complex. Case study research necessarily takes a particular stance, as in this case study by the provision of a relevant naturalistic setting. ADR turned out to be suitably pragmatic, capturing organisational and technical aspects of the intervention in a 'meta-approach' to evaluation. However, no stance is isolated. It resonates with other approaches and these are worth indicating.

Firstly, over the last decade there has been an evolution in thinking about design research and it now presents a complex picture. The ADR framework from Sein et al. (2011) was selected as the basis of this research, but is one of many that could have been chosen. One of the reasons for its selection was its recognition of the process of artefact development, not just products, through cycles of evaluation to realise an ensemble artefact. In an era of agile development, the Sein framework may seem rather traditional yet the research reported here suggests that the agile development of artefact components, independent of the involvement of all stakeholders, misses out on some significant benefits that can accrue along with systems development. In particular, this research shows that stakeholder-engaged project development can have much wider impacts in terms of improved systems literacy within an organisation, and increased technological engagement, that attitudes change, from systems being seen as necessary evils to them being positive contributors to the organisation. This was unexpected as the systems being developed were 'back office systems' which are usually recognised prosaically in terms of efficiency and effectiveness.

Secondly, there are interwoven design trends and conceptual themes that complement the findings of this paper, for example, Value Sensitive Design (Yoo, Huldtgren, Palzkill Woelfer, Hendry and Friedman 2013) and User Experience Design (Adikari, McDonald and Campbell 2013). In parallel with Sein et al. (2011), these themes, in their own ways, shift the focus of ICT evaluation from the product's behaviour to its relationship with stakeholders. In future, a coalition of research approaches sharing a similar approach may yield greater benefits than single approaches alone. 
Thirdly, research is often conceived as being for the researcher in their search for knowledge accumulation. However 'transformative research' (for example, that advocated by Malhotra, Melville, and Watson 2013) promotes the benefits possible for all stakeholders. In this case, while the researchers are producing results for the research community, the organisation is benefitting greatly (through facilities provision and shifts in attitude towards greater engagement with their own systems) as are the students (through authentic development experience). This project is having transformative affects and is showing emergent gains beyond the initial goals of stakeholders, especially attitudinal and educational for all participants.

Lastly, the NFP sector's use of BI as a strategic focus is of importance from many different perspectives. The number of people and devices interconnected is set to grow massively in the next few years. All this data is creating an opportunity for BI to become essential in the decision-making process with the aim of improving the outcome of these decisions. Crump and Raja (2013) report on findings taking a different technology approach, that of shared services for NFPs. They are interested in evaluating organisational readiness to assess and adopt different kinds of ICT systems - an approach that would complement the research reported here.

\section{Concluding Remarks}

This paper proposes iterative and holistic stakeholder evaluations through integration of content, context and process (CCP) appraisals into Action Design Research (ADR) to complement more prescribed technology-driven project and software testing. The CCP framework focusses on qualitative human-focussed evaluation and is useful in providing both descriptive knowledge about natural phenomena as well as prescriptive knowledge (Gregor and Hevner 2013) through design principles. This socio-technical method of evaluation meshes well with ensemble artefact design and development such as BI software. Sein et al. (2011) recognise that a case study using ADR is highly situated, offering the potential of theorising from the specific and unique to the generic and abstract. From the outset, the project being analysed in this paper had dual purposes - to make a difference in the case study site, Connections ACT, and to use the experience to create a set of analytic, design, intervention and evaluation guidelines for general use in the not-for-profit sector. This paper is a step towards those dual purposes.

Sein et al. (2011, p.45) argue that "design principles capture the knowledge gained about the process of building solutions for a given domain, and encompass knowledge about creating other instances that belong to this class". A number of design principles are emerging from the case study that apply generally. Some examples include the use of open source software and cloud warehousing, project development with WIL students supported by community experts and facilitated by academic researchers, CCP evaluations for qualitative stakeholder appraisals, and the concept of small wins, akin to Gregor et al.'s 'sweet spot' (Gregor et al. 2010).

The third purpose is to extend ADR knowledge through empirical research. The quadrant which is most apt is Exaptation: Known Solutions Extended to New Problems. Gregor and Hevner (2013, p.347) describe this as “... contributions where design knowledge that already exists in one field is extended or refined so that it can be used in some new application area". TheADR generic schema for BIE (Sein et al. 2011) illustrated in Figure 1is intended for projects in commercial settings. This paper extends the model into the NFP sector with multiple iterations for WIL student-built IT artefacts. The paper does not articulate minutiae of artefact design, stakeholder participation and artefact appropriation. These are the domains of other papers.

In light of our ADR study set in a NFP, we now put forward an alternative definition of evaluation than the one from Cleven et al. (2009) cited earlier. This definition incorporates the evaluation view of an ensemble artefact: 
Evaluation is the process of determining the quality of the design and development of an ensemble artefact, being context, content and the process itself. Evaluations may be social or technical, formal or informal, qualitative or quantitative or a mix of these. Along with interventionist practices, critical reflections and learning are outcomes of the evaluative process.

\section{References}

Adikari, S., McDonald, C. and Campbell, J . (2013) "Agile User Experience Design: A Design Science Enquiry" Proceedings of the 24th Australasian Conference on Information Systems (ACIS), RMIT Melbourne Vic.

Arnott, D. and Pervan, G. (2005) "A critical analysis of decision support systems research" J ournal of Information Technology, 20(2), 67- 87.

Arnott, D. and Pervan, G. (2008) "Eight key issues for the decision support systems discipline" Decision Support Systems, 44(3), 657-672.

Arnott, D. and Pervan, G. (2012) 'Design Science in Decision Support Systems Research: An Assessment using the Hevner, March, Park, and Ram Guidelines" J ournal of the Association for Information Systems, 13(11), 923-949.

Baskerville, R. (2008) "What design science is not" European Journal of Information Systems, Editorial, 17, 441- 443.

Cleven, A., Gubler, P. and Hűner, K. (2009) "Design Alternatives for the Evaluation of Design Science Research Artifacts" Proceedings of the International Conference DESRIST 2009, Malvern PA USA.

Cole, R., Purao, S., Rossi, M. and Sein, M. (2005) "Being Proactive: Where Action Research meets Design Research" Proceedings of the 26 $6^{\text {th }}$ International Conference on Information Systems (ICIS), Las Vegas USA.

Crump, B. and Raja, P. (2013) "A Case for Non-Profit Organisations to engage in the use of Shared Computing Services" Electronic J ournal of Information Systems Evaluation, 16(4), 270-277.

Davison, R. M. and Martinsons, M. G. (2004) "Principles of Canonical Action Research" Information Systems J ournal, 14(1), 65-86.

Fidock, J ., Carroll, J . and Rynne, A. (2010) “Evaluating Information Systems: an appropriation perspective" in D. Hart and S. Gregor (eds) Information Systems Foundation: The Role of Design Science, ANU ePress, Canberra ACT.

Fitch, K. (2011) “Developing Professionals: student experiences of a real-client project” Higher Education Research \& Development, 30(4), 491-503.

Goldkuhl, G. (1981) "Systemering som formalisering av människors språk - en humaninfologisk teori" [in Swedish] NordDATA81, Copenhagen.

Goldkuhl, G. (2012) "Design Research in search for a Paradigm: Pragmatism is the answer" in M. Helfert, and B. Donnellan (eds) Practical Aspects of Design Science - Proceedings EDSS2011, Springer, Berlin.

Goldkuhl, G. (2013) "From Ensemble View to Ensemble Artefact - An Inquiry on Conceptualizations of the IT Artefact" Systems, Signs \&Actions, 7(1), 49-72.

Goldkuhl, G. and Sjöströmb. J . (2015) "Closing the practice loop: Practice design research" Proceedings of the AIS SIGPRAG Pre-ICIS Workshop 2015 Practice-based Design and Innovation of Digital Artifacts.

Gregor, S. (2006) “The Nature of Theory in Information Systems” MIS Quarterly, 30(3), 611642. 
Gregor, S. and Hevner, A. (2013) "Positioning and Presenting Design Science Research for Maximum Impact”, MIS Quarterly. 37(2), 337-355.

Gregor, S., Imran, A. and Turner, T. (2010) “Designing for a 'Sweet Spot' in an Intervention in a Least Developed Country: the Case of e-Government in Bangladesh" Proceedings of SIG GlobDev $3^{\text {rd }}$ Annual Workshop, St Louis USA.

Hevner, A., March, S., Park, J . and Ram, S. (2004) "Design Science in Information Systems Research" MIS Quarterly, 28(1), 75-195.

Houghton, L. and MacKrell, D. (2014) "Sensemaking as Feral Information Systems: Conceptual and Framework Development" in L. Houghton and D. Kerr (eds)_Feral Information Systems, Idea Group Inc. Hershey PA USA.

Iivari, J . and Venable, J . (2009) "Action research and design science research - Seemingly similar but decisively dissimilar" Proceedings of the 17th European Conference in Information Systems (ECIS). Verona Italy.

Järvinen, P. (2007) “Action Research is Similar to Design Science” Quality \&Quantity. 41, 3754.

Klawans, B. (2006) "Saving Time and Money - Why Open-Source BI Makes Sense” Business Intelligence J ournal. 11(4), 18-24.

Koparkar, P. and MacKrell, D. (2015) "How Fluffy is the Cloud ?: Cloud Intelligence for a NotFor-Profit" Proceedings of the 26 $6^{\text {th }}$ Australasian Conference on Information Systems (ACIS), University of South Australia, Adelaide SA.

Maccani, G., Donnellan, B. and Helfert, M. (2015) "Action design research: a comparison with canonical action research and design science" in B. Donnellan, R. Gleasure, M. Helfert, J. Kenneally, M. Rothenberger, M. Chiarini Tremblay, D. Vandermeer, and Winter, R. (eds.) At the Vanguard of Design Science: First Impressions and Early Findings from Ongoing Research, Research-in-Progress Papers and Poster Presentations from the $10^{\text {th }}$ International Conference DESRIST 2015. Dublin Ireland, 20-22 May. 69-76.

McKay, J . and Marshall, P. (2001) "The dual imperatives of action research" Information Technology and People, 14(1), 46-59.

McKay, J., Marshall, P. and Heath G. (2010) "An Exploration of the Concept of Design in Information Systems" in Hart \& Gregor (eds). Information Systems Foundation: The Role of Design Science, ANU ePress, Canberra ACT.

MacKrell, D. (2012) "Delivering Optimal Health Outcomes: Making Sense of a Business Intelligence Decision in a Not-for-Profit Organisation" Proceedings of the Pacific Asia Conference on Information Systems (PACIS). Ho Chi Minh City Vietnam.

MacKrell, D. and McDonald, C. (2014) "Action Design Research: a Case Study of Business Intelligence in Non-Profit Organizations" Proceedings of the SIGDSS IFIP WG 8.3 International Conference, University Pierre and Marie Curie (UPMC) Paris.

MacKrell, D. and Van Den Boogaard, M. (2012) "Socio-Technical Framework for Improved Decision-making in Not-for-Profit Organisations" Proceedings of the 23 ${ }^{\text {rd }}$ Australasian Conference on Information Systems (ACIS). Deakin University, Geelong Vic.

Malhotra, A., Melville, N. and Watson, R. (2013) "Spurring Impactful Research on Information Systems for Environmental Sustainability" MIS Quarterly, 37(4), 1265-1274, December.

March, S. and Smith, G. (1995) "Design and natural science research on information technology" Decision Support Systems, 15(4), 251-266.

Markus, M., Majchrzak, A. and Gasser, L. (2002) "A Design Theory for Systems That Support Emergent Knowledge Processes” MIS Quarterly, 26(3), 179-212. 
Markus, M. and Mao, J. (2004) "Participation in Development and Implementation Updating an Old, Tired Concept for Today's IS Contexts" J ournal of the Association for Information Systems, 5(11-12), 514-544.

Miah, S. and Gammack, J . (2014) "Ensemble Artifact Design for Context Sensitive Decision Support" Australasian J ournal of Information Systems, 18(2), 5-20.

Orlikowski, W. J . and Iacono, C. S. (2001) "Desperately seeking the "IT" in IT research - a call to theorizing the IT artefact” Information Systems Research, 12(2), 121-134.

Papas, N., O’Keefe, R. and Seltsikas, P. (2012) 'The action research vs design science debate: reflections from an intervention in eGovernment" European J ournal of Information Systems, 21(2), 147- 159.

Pries-Heje, J ., Baskerville, R. and Venable, J . (2008) "Strategies for Design Science research Evaluation" Proceedings of the European Conference on Information Systems (ECIS), Galway Ireland.

Purao, S., Henfridssonb, O., Rossi, M. and Sein, M. (2013) "Systems Ensemble Artifacts: From Viewing to Designing in Action Design Research” Signs \&Actions, 7(1), 73- 81.

Scriven, M. (1998) "The new science of evaluation" International J ournal of Social Welfare, 7(2), 79-86.

Sein, M., Henfridsson, O., Purao, S., Rossi, M. and Lindgren, R. (2011) “Action design research” MIS Quarterly, 35(1), 35-56.

Sharda, R., Delen, D. and Turban, E. (2014) Business Intelligence and Analytics Systems for Decision Support, $10^{\text {th }}$ Edition, Pearson.

Stockdale, R. and Standing, C. (2006) "An interpretive approach to evaluating information systems: A content, context, process framework" European J ournal of Operational Research, (173), 1090-1102.

Symons, H. (1991) "A review of IS systems evaluation: content, context and process”. European J ournal of Information Systems (EJ IS), 1(3), 205-212.

Venable, J. (2006) "The Role of Theory and Theorising in Design Science Research" Proceedings of the $1^{\text {st }}$ International Conference on Design Science (DESRIST). Claremont CA USA.

Weick, K. (1984) "Small Wins: Redefining the Scale of Social Problems" American Psychologist, 39(1), 40-49.

Weick, K. (1995) Sense-making in Organizations, Sage Publications, Thousand Oaks CA.

Winter, R. (2008) "Design science research in Europe” European J ournal of Information Systems, 17, 470-475.

Yoo, D., Huldtgren, A., Palzkill Woelfer, J., Hendry, D. and Friedman, B. (2013) "A value sensitive action-reflection model: evolving a co-design space with stakeholder and designer prompts" Proceedings of the SIGCHI Conference on Human Factors in Computing Systems (CHI '13), 419-428.

Copyright: (C) 2016 MacKrell \& McDonald. This is an open-access article distributed under the terms of the Creative Commons Attribution-NonCommercial 3.0 Australia License, which permits non-commercial use, distribution, and reproduction in any medium, provided the original author and AJ IS are credited. 


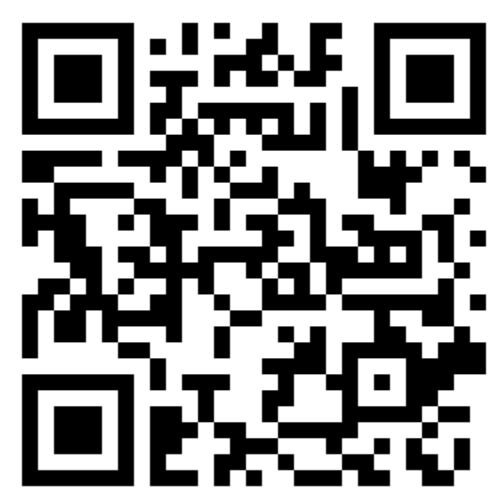

